4. Bonilla, M.A., Gillo, A.P., Ruffeiro, M. et al. Effects of recombinant human granulocyte colony stimulating factor on neutropaenia in patients with congenital agranulocytosis. $N$ Engl J Med 1989, 320: 1574-1580.

5. Bronchud, M.D., Potter, M.R., Morgenstern, G. et al. In vitro and in vivo analysis of the effects of recombinant human granulocyte colony stimulating factor in patients. $\mathrm{Br} \mathrm{J}$ Cancer 1988, 58: 64-69.

6. Gerson, S.L., Gullion, G., Yeh, H.S. \& Masor, C. Granulocyte colony-stimulating factor for clozapine induced agranulocytosis. Lancet 1992, 340: 1097.
7. Weide, R., Koppler, H., Heymanns, J., Pfluger, K.H. \& Havemann, K. Successful treatment of clozapine induced agranulocytosis with G-CSF. Br J Haematol 1992, 80: 557-559.

8. Patton, W.N., Holyoake, T.L., Yates, J.M., Boughton, B.J. \& Franklin, I.M. Accelerated recovery from drug induced agranulocytosis following G-CSF therapy. Br J Haematol 1992, 80: 564-565.

\title{
Type IV renal tubular acidosis and spironolactone therapy in the elderly
}

\author{
J.E. O'Connell* and N.R. Colledge
}

Geriatric Medicine Unit, University of Edinburgh, City Hospital, Greenbank Drive, Edinburgh EH10 5SB, UK

\begin{abstract}
Summary: Spironolactone therapy is a well-known cause of hyperkalaemia, but in susceptible patient, it may also be associated with metabolic acidosis. We report a case of severe renal tubular acidosis (Type IV) with life-threatening hyperkalaemia caused by spironolactone, and discuss the mechanisms by which this may occur.
\end{abstract}

\section{Introduction}

Approximately one-fifth of people aged over 65 years take some form of diuretic. ${ }^{1}$ In order to prevent associated hypokalaemia it is common practice to co-prescribe potassium supplements or to use a potassium-sparing diuretic. It is well known that the latter should be avoided in renal failure, but the risk of significant hyperkalaemia in elderly subjects with mild renal impairment is less well recognized. ${ }^{2}$ We describe the case of an 88 year old woman who developed life-threatening hyperkalaemia with distal renal tubular acidosis (type IV) while on treatment with spironolactone.

\section{Case report}

An 88 year old woman was admitted to hospital with fluctuating confusion, slurred speech and inability to weight bear of sudden onset. She had a past history of hypertension, congestive cardiac

Correspondence: N.R. Colledge, B.Sc., M.R.C.P. *Present address: Dryburn Hospital, Durham, UK. Accepted: 1 April 1993 failure, bilateral lower leg ulceration, hyperuricaemia and poor mobility due to osteoarthritis. Her daily medication included spironolactone $200 \mathrm{mg}$, frusemide $80 \mathrm{mg}$, allopurinol $100 \mathrm{mg}$, quinine sulphate $300 \mathrm{mg}$ and co-codamol (paracetamol and codeine) as required for pain.

Physical examination revealed a mentally alert, obese lady with a pulse of 88 beats/minute and a blood pressure of $170 / 90 \mathrm{mmHg}$. There was no postural drop in blood pressure. Skin turgor was reduced and the jugular venous pulse could not be demonstrated, although there was a trace of ankle oedema. Auscultation of her chest revealed bilateral basal inspiratory crepitations. She had a mild right hemiparesis, and a right VII nerve palsy of upper motor neurone type with associated dysarthria.

Serum biochemistry on admission showed urea $27.2 \mathrm{mmol} / 1$ (normal range $2.5-6.6 \mathrm{mmol} / \mathrm{l}$ ), creatinine $235 \mu \mathrm{mol} / \mathrm{l}$ (normal range 55-150 $\mu \mathrm{mol} / \mathrm{l}$ ), sodium $129 \mathrm{mmol} / \mathrm{l}$ (normal range 132 $144 \mathrm{mmol} / \mathrm{l}$ ) and potassium $7.6 \mathrm{mmol} / 1$ (normal range 3.3-4.7 mmol/l). Arterial blood gas analysis revealed a metabolic acidosis (hydrogen ion $51 \mathrm{nmol} / 1$, normal range $34-44 \mathrm{nmol} / \mathrm{l}$; bicar- 
bonate $12 \mathrm{mmol} / 1$, normal range $21-27 \mathrm{mmol} / \mathrm{l}$, $\mathrm{PO}_{2} 16.5 \mathrm{kPa}$, normal range $12-15 \mathrm{kPa}, \mathrm{PCO}_{2}$ $3.1 \mathrm{kPa}$, normal range $4.4-6.1 \mathrm{kPa}$ ). Random blood glucose concentraton was $8.8 \mathrm{mmol} / 1$. Urine $\mathrm{pH}$ was 5.0 . The anion gap was $20.3 \mathrm{mmol} / \mathrm{l}$ (normal $20 \mathrm{mmol} / \mathrm{l})$. An electrocardiogram showed sinus rhythm with first degree block, peaked $T$ waves and widened $Q R S$ complexes. These findings were in keeping with a diagnosis of distal renal tubular acidosis (Type IV).

Spironolactone and frusemide therapy was discontinued. She received intravenous dextrose and insulin, $1.26 \%$ sodium bicarbonate, and $10 \%$ calcium gluconate, along with oral calcium polystyrene sulphonate resin (calcium resonium). Her hyperkalaemia proved resistant to therapy, requiring continuous intravenous bicarbonate for 48 hours, and oral therapy with sodium bicarbonate and calcium resonium for one week (Figure 1).

Subsequently renal ultrasound examination showed small kidneys (R9.8 cm, L9.9 cm). Addison's disease was excluded with plasma cortisol rising from $616 \mathrm{nmol} / 1$ to $860 \mathrm{nmol} / 1$ following $250 \mu \mathrm{g}$ Synacthen. Dribbling urinary incontinence precluded a 24 hour urine collection for estimation of creatinine clearance and potassium excretion, and her poor mobility prevented estimation of erect and supine renin and aldosterone levels.

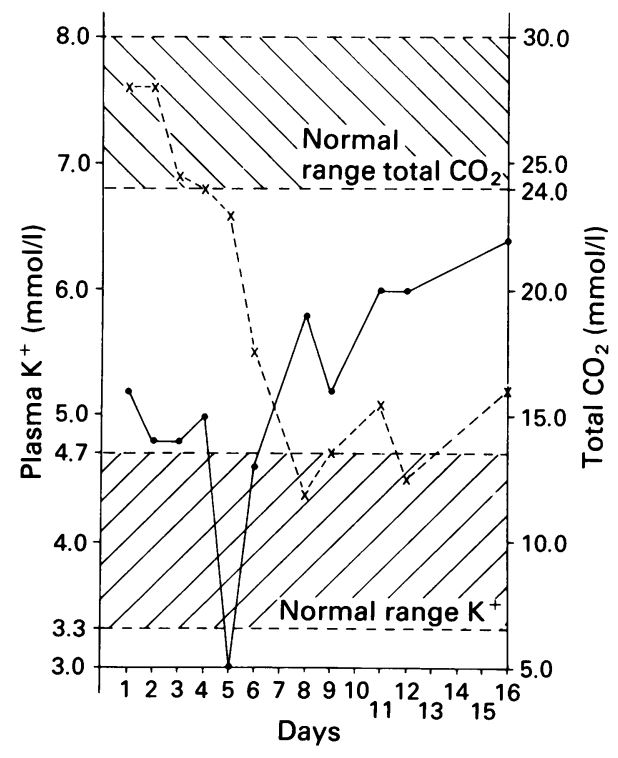

Figure 1 Changes in plasma potassium $\left(\mathrm{K}^{+}\right)$and venous bicarbonate (total $\mathrm{CO}_{2}$ ) concentrations in an 88 year old woman following cessation of spironolactone therapy. Plasma $\mathrm{K}^{+}$is represented by the broken line, and total $\mathrm{CO}_{2}$ by the solid line. Normal ranges for $\mathrm{K}^{+}$and total $\mathrm{CO}_{2}(\mathrm{mmol} / \mathrm{l})$ are shown by the shaded areas.
The patient's neurological signs improved ڤ rapidly following correction of her biochemical $\underset{3}{3}$ abnormalities. Her biochemistry on discharge from $\stackrel{\mathbb{Q}}{\propto}$ hospital was as follows: sodium $133 \mathrm{mmol} / \mathrm{l}$, potas-.. sium $4.8 \mathrm{mmol} / 1$, urea $9.8 \mathrm{mmol} / 1$, creatinine $\Rightarrow$ $118 \mu \mathrm{mol} / \mathrm{l} ;$ her electrocardiogram had returned to normal.

\section{Discussion}

Type IV renal tubular acidosis is associated with a $\vec{\circ}$ generalized impairment of distal tubular function, usually on a background of moderate reduction of $\vec{\omega}$ the glomerular filtration rate such as occurs with ageing. ${ }^{3}$ It occurs in many hyperkalaemic states and is thought not to represent a single patho- 3 . physiological entity, although most patients have \& low circulating levels of aldosterone or a decrease $\stackrel{\infty}{\rightarrow}$ in the tubular response to this hormone. It is $\vec{v}$ characterized by a normal ability to maintain a $\stackrel{\infty}{\infty}$ hydrogen ion gradient and thus to acidify the urine after an acid load. Bicarbonate wasting is present at normal plasma bicarbonate concentrations, al- $\vec{z}$ though this is not of sufficient degree to implicate a proximal tubular defect. The underlying abnormality is a decrease in ammonia production and excretion which is thought to be a direct result of $\mathbb{D}$ the increase in intracellular potassium. It can bo $\vec{\theta}$ found in primary aldosterone deficiency due to. Addison's disease, but also occurs as a direct consequence of spironolactone therapy which competitively blocks the action of aldosterone on the distal tubule, and in association with renal insufficiency and volume contraction. ${ }^{4}$ It may also arise because of disease of the juxtaglomerular apparatus which causes impaired production of renin and secondary hypoaldosteronism, a condition known as hyporeninaemic hypoaldosteronism. ${ }^{3}$ This is common in the elderly, and has been described in association with diabetes mellitus, hypertension, ${ }^{5}$ urinary tract obstruction, ${ }^{6}$ and drugs which inhibit the renin-angiotensin system such as beta-blockers and prostaglandin synthetase inhibitors. $^{2}$

We believe that our patient had mild underlying hyporeninaemic hypoaldosteronism and that she developed severe hyperkalaemia as a result of the addition of spironolactone. Spironolactone has a duration of action of up to 5 days which might explain why our patient's metabolic derangement was initially resistant to conventional therapy. Continuation of her frusemide therapy might have increased potassium excretion, but would have worsened her possible volume depletion,

The hyperkalaemia of hyporeninaemic hypoaldosteronism may be treated with fludrocortisone or a loop diuretic, ${ }^{2}$ although the use of either in the elderly is limited by side effects, such as fluid 
retention with fludrocortisone, and hyponatraemia and postural hypotension with loop diuretics.

This case illustrates the risks of treatment with spironolactone in elderly subjects with mild renal impairment. Hyperkalaemia is a life-threatening complication to which the elderly are prone because of the physiological changes in renal

\section{References}

1. MacLennan, W.J. Diuretics in the elderly: how safe? Br Med J 1988, 296: 1551 .

2. Michelis, M.F. Hyperkalaemia in the elderly. Am J Kidney Dis 1990, 16: 296-299.

3. Tan, S.Y. \& Burton, M. Hyporeninemic hypoaldosteronism. An overlooked cause of hyperkalaemia. Arch Intern Med 1981, 141: $30-33$.

4. Rodriguez-Soriano, J. Renal tubular acidosis. In: Cameron, S., Davison, A.M., Grunfeld, J.P., Kerr, D. \& Ritz, E. (eds) Oxford Textbook of Clinical Nephrology, Vol. 1. Oxford University Press, Oxford, 1992, pp. 763-781. function associated with ageing. Other potassium sparing drugs such as amiloride have a much shorter duration of action and therefore in theory may be safer, but in general all such drugs should be used with extreme caution in the elderly and their metabolic effects closely monitored.

5. Large, D.M., Carr, P.H., Laing, I. \& Davies, M. Hyperkalaemia in diabetes mellitus - potential hazards of coexisting hyporeninemic hypoaldosteronism. Postgrad Med J 1984, 60: 370-373.

6. O'Reilly, P.H., Upsdell, S.M. \& Brough, R.J. Life-threatening hyperkalaemia after bladder decompression for high pressure chronic retention. Lancet 1987, ii: 859. 